\title{
Boron Toxicity Causes Multiple Effects on Malus domestica Pollen Tube Growth
}

\author{
Kefeng Fang ${ }^{\dagger}$, Weiwei Zhang ${ }^{\dagger}$, Yu Xing, Qing Zhang, Liu Yang, Qingqin Cao and \\ Ling Qin*
}

Beijing Key Laboratory for Agricultural Application and New Technique, College of Plant Science and Technology, Beijing University of Agriculture, Beijing, China

Boron is an important micronutrient for plants. However, boron is also toxic to cells at high concentrations, although the mechanism of this toxicity is not known. This study aimed to evaluate the effect of boron toxicity on Malus domestica pollen tube growth and its possible regulatory pathway. Our results showed that a high concentration of boron inhibited pollen germination and tube growth and led to the morphological abnormality of pollen tubes. Fluorescent labeling coupled with a scanning ion-selective

OPEN ACCESS

Edited by:

Sylvain Jeandroz, AgroSup Dijon, France

Reviewed by:

Frantisek Baluska,

University of Bonn, Germany

Jorge Muschietti,

Institute for Research

in Genetic Engineering and Molecular

Biology (INGEBI), Argentina

*Correspondence:

Ling Qin

qinlingbac@126.com

tThese authors have contributed equally to this work.

Specialty section: This article was submitted to Plant Physiology,

a section of the journal

Frontiers in Plant Science

Received: 17 December 2015 Accepted: 06 February 2016 Published: 26 February 2016

Citation:

Fang $K$, Zhang $W$, Xing $Y$, Zhang $Q$, Yang L, Cao Q and Qin L (2016) Boron Toxicity Causes Multiple Effects on Malus domestica Pollen Tube Growth. Front. Plant Sci. 7:208. doi: 10.3389/fp/s.2016.00208 electrode technique detected that boron toxicity could decrease $\left[\mathrm{Ca}^{2+}\right] \mathrm{c}$ and induce the disappearance of the $\left[\mathrm{Ca}^{2+}\right] \mathrm{c}$ gradient, which are critical for pollen tube polar growth. Actin filaments were therefore altered by boron toxicity. Immuno-localization and fluorescence labeling, together with fourier-transform infrared analysis, suggested that boron toxicity influenced the accumulation and distribution of callose, de-esterified pectins, esterified pectins, and arabinogalactan proteins in pollen tubes. All of the above results provide new insights into the regulatory role of boron in pollen tube development. In summary, boron likely plays a structural and regulatory role in relation to $\left[\mathrm{Ca}^{2+}\right] \mathrm{c}$, actin cytoskeleton and cell wall components and thus regulates Malus domestica pollen germination and tube polar growth.

Keywords: Malus domestica, boron toxicity, calcium, actin, callose, pectin, arabinogalactan proteins

\section{INTRODUCTION}

Boron is an essential micronutrient for the normal development of higher plants (Blevins and Lukaszewski, 1998). Its main role is to form borate-diol ester bonds to link two rhamnogalacturonan II (RGII) chains of pectic polysaccharide (Pérez-Castro et al., 2012; Funakawa and Miwa, 2015). Recent research illustrated that boron also cross-link glycosylinositol phosphorylcer amides of the plasma membrane with arabinogalactan proteins (AGPs) of the cell wall, thereby attaching the membrane to the cell wall (Tenhaken, 2014; Voxeur and Fry, 2014). Thus, boron is known to affect the mechanical properties of the cell wall (Dumont et al., 2014). There is a narrow range of favorable boron concentrations for plant development. Abnormal levels of boron can be toxic or can trigger deficiency symptoms (Pérez-Castro et al., 2012). The optimum boron level for one species can be either toxic or insufficient for other species (Blevins and Lukaszewski, 1998). Boron toxicity is an important agricultural problem that limits crop productivity (Nable et al., 1997) and attracts increase interest. Boron toxicity has been shown to affect several developmental or biochemical processes in plants (Sakamoto et al., 2011), including 
inhibiting the formation of glutathione (Ruiz et al., 2003) and tocopherol (Keles et al., 2004), reducing root cell division (Aquea et al., 2012), and shoot cell wall expansion (Loomis and Durst, 1992), decreasing fruit number, size and weight, formatting reactive oxygen species(ROSs) (Paull et al., 1992; Nable et al., 1997; Karabal et al., 2003; Cervilla et al., 2007), increasing oxidative damage (Gunes et al., 2006; Molassiotis et al., 2006; Sotiropoulos et al., 2006), affecting the photosynthesis and antioxidant apparatus (Landi et al., 2013), and leading to DNA damage (Sakamoto et al., 2011). A cDNA-AFLP analysis revealed that long-term boron stress induced changes related to signal transduction, metabolism of carbohydrate, energy, nucleic acid, protein, amino acid and lipid, cell wall and cytoskeleton modification, stress responses, and cell transport in Citrus grandis and Citrus sinensis (Guo et al., 2014). Furthermore, several genes involved in plant tolerance to boron stress have been identified, including Arabidopsis thaliana BOR4 and TIP5;1 (Miwa et al., 2007; Pang et al., 2010), barley (Hordeu mvulgare) Bot1 (Sutton et al., 2007), wheat and barley HvBOR2 (Reid, 2007), and citrus (Citrus macrophylla) CmBOR1 (Cañon et al., 2013). These genes encode transport molecules that exclude excess boron or regulate intracellular boron homeostasis to prevent boron stress (Sakamoto et al., 2011). Although a number of studies have been performed in this field, as described above, the effects of boron toxicity on sexual plant reproduction remain largely unknown.

Pollen tubes represent a fast growing system that requires boron to germinate and maintain tube elongation (Taylor and Hepler, 1997), making it a good system with which to investigate the influence of boron toxicity. Pollen tubes are cells that grow from their tips, whose elongation exhibits a polarized pattern (Hao et al., 2013). During the process of pollen tube growth, large amounts of membrane, and cell wall precursors are transported by the secretory vesicles derived from the Golgi apparatus to the tip to form the new cell wall and thus lead to pollen tube elongation (Taylor and Hepler, 1997; Ketelaar et al., 2008; Moscatelli and Idilli, 2009; Zhang et al., 2010; Bou and Geitmann, 2011). The pollen tube wall is mainly composed by cellulose, callose, and pectins, among which the pectins seem to be the major component of the cell wall ( $\mathrm{Li}$ et al., 1996, 2002; Ferguson et al., 1998). The Golgi apparatus produced esterified pectin residues and the latter is secreted at the extreme apex of the pollen tube (Hasegawa et al., 1998). The esterified pectins are de-esterified by the enzyme pectin methyl-esterase (PME) when arrival at the cell wall (Geitmann, 1999; Li et al., 2002). De-esterification of pectin produces acidic residue which cross-links $\mathrm{Ca}^{2+}$ ions to form a semi rigid pectate gel (Braccini and Perez, 2001), thus providing mechanical support for the elongating tube. Esterified pectins are mainly present at the apex and speculated to allow tube expansion (Franklin-Tong, 1999). Therefore, de-esterified and esterified pectins control jointly the growth of plant cell (Wolf and Greiner, 2012).

Boron is necessary for pollen tubes (Obermeyer et al., 1996), and affects pollen tube morphology and tube growth (Dickinson, 1978; Holdaway-Clarke and Hepler, 2003). However, few data are available on the effects of boron toxicity on pollen germination and tube growth. The detailed regulatory effects of boron toxicity on pollen tube development remain to be elucidated.

In the present study, Malus domestica pollen was chosen as the material with which to study the influence of boron toxicity on germination and pollen tube growth, focusing on the dynamics of calcium, actin, and cell wall components. Our results revealed that boron toxicity could interrupt the calcium gradient at the tip of a pollen tube and block its polar growth, likely via disturbing the actin organization and thus disturbing the cell wall material directional transportation and cell wall construction.

\section{MATERIALS AND METHODS}

\section{Plant Materials and Pollen Culture}

Mature pollen grains were collected from Malus domestica trees grown in Henan Province on April 10, 2014. The collected pollen grains were dried on paper towels and then stored in vials at $-20^{\circ} \mathrm{C}$ until use.

The basal medium for pollen tube growth was composed by $20 \%(\mathrm{w} / \mathrm{v})$ sucrose and $0.01 \% \mathrm{CaCl}_{2}, \mathrm{pH}$ 6.8. Pollen grains was placed into culture medium in concentration of $1.0 \mathrm{mg} \mathrm{mL}{ }^{-1}$. Different concentrations of boric acid (Sigma, St. Louis, MO, USA) was added to the medium at the beginning of incubation. The culture with shake for $100 \mathrm{rpm}$ at $30^{\circ} \mathrm{C}$ in the darkness.

Method of Dafni (2000) was used to determine the pollen germination rates under BX51 microscope which is equipped with a CoolSNAP HQ CCD camera (Photometrics) after $2 \mathrm{~h}$ of incubation. The lengths of pollen tubes were measured using MetaMorph (Universal Imaging) after $2 \mathrm{~h}$ of incubation. All experiments were performed in triplicate and at least 150 pollen tubes were measured in each experiment. Viability of the pollen tube was detect with fluorescein diacetate (FDA) according to Chebli et al. (2013).

\section{Measurement of Extracellular $\mathrm{Ca}^{2+}$ Influx}

Net $\mathrm{Ca}^{2+}$ fluxes of pollen tubes were measured in the Younger USANMT Service Center (Xuyue Beijing) using a Non-invasive Micro-test Technique (NMT-YG-100, Younger USALLC, Amherst, MA01002, USA) with the ASET 2.0 (Sciencewares, Falmouth, MA 02540, USA) and the iFluxes 1.0 (Younger USA, LLC, Amherst, MA 01002, USA) software packages (Wang et al., 2013). Excel sheet (Microsoft) was employed to analyze the obtained data and convert data into ion influx ( $\mathrm{pmol} \mathrm{cm} \mathrm{cm}^{-2} \mathrm{sec}^{-1}$ ) accordingly.

\section{Labeling of Cytoplasmic $\left[\mathrm{Ca}^{2+}\right] \mathrm{c}$}

Fluo-3/AM ester was loaded into pollen tubes to label cytoplasmic $\left[\mathrm{Ca}^{2+}\right] \mathrm{c}$ at low temperature in the dark at a final concentration of $10 \mu \mathrm{M}$, as described previously (Zhang and Renzel, 1998). After $1 \mathrm{~h}$ of incubation, the pollen tubes were washed with standard medium several times and placed under room temperature for $1 \mathrm{~h}$. After that the pollen tubes photographed using a Leica TCS SP5 laser-scanning confocal microscope (LSCM) (Leica Co., Germany) with excitation at $488 \mathrm{~nm}$ and emission at $515 \mathrm{~nm}$. 


\section{Fluorescent Labeling of Actin Filament}

Fluorescent labeling of actin filament was according to Hao et al. (2013). Control and boron toxicity treated pollen tubes were fixed in a freshly prepared solution of $4 \%$ paraformaldehyde in PBS ( $\mathrm{pH}$ 6.9) for $1.5 \mathrm{~h}$ at room temperature, followed by three washes with PBS, and treated with enzyme solution containing $1 \%$ cellulase $\mathrm{R}-10$ and $1 \%$ pectinase at $37^{\circ} \mathrm{C}$ for $15 \mathrm{~min}$. Then the pollen tubes were washed in PBS, and incubated in $1 \%$ Triton X100 at room temperature for $1 \mathrm{~h}$. After three times with PBS, the pollen tubes were incubated in $0.2 \mu \mathrm{M}$ phalloidin-FITC (Sigma, USA) in PBS (pH 6.9) buffer for $2 \mathrm{~h}$ in darkness (Hao et al., 2013). Then, the pollen tubes were washed with PBS and observed under the LSCM with Excitation at $488 \mathrm{~nm}$ and emission at $515 \mathrm{~nm}$.

\section{Localization and Analysis of Cell Wall Components}

Calcofluor was employed to stain cellulose as described by Lazzaro et al. (2003), callose was stained with $0.05 \%$ aniline blue according to Chen et al. (2007). The stained pollen tubes were observed and photographed under a FSX100 microscope (Olympus, Japan). Method described by Chen et al. (2007) was used to label pectins and AGPs of pollen tubes. The labeled pollen tubes were observed under the LSCM with excitation at $488 \mathrm{~nm}$ and emission at $515 \mathrm{~nm}$. Values for fluorescence intensity was analyzed according to Chebli et al. (2013). At least 10 tubes were analyzed for each treatment, which was repeated three times. Fourier Transform Infrared (FTIR) spectroscopy analysis of wall components was performed according to Hao et al. (2013). At least 10 tubes were analyzed for each treatment, which was repeated three times.

\section{RESULTS}

\section{Boron Toxicity Affected Pollen Germination and Tube Growth}

Boron affected pollen tube morphology (Figure 1). In germination medium including $20 \%$ sucrose, $0.015 \% \mathrm{CaCl}_{2}$ and $0.01 \% \mathrm{H}_{3} \mathrm{BO}_{3}$, pollen tubes appeared healthy with a regular shape. The constant diameter is illustrated in Figure 1A. The morphology of pollen tubes treated with high concentrations of boron was abnormal: the pollen tube was short, the tip of the tube swelled, and the diameter of the tube increased (Figures 1B,C). Strong FDA fluorescence indicated the viability of the swollen tube (Figure 1D).

Boron affects pollen germination and tube growth in a dosedependent manner. Apple pollen grain has been reported to contain $55.45 \mu \mathrm{g} / \mathrm{g}$ boron (Gao et al., 2014), and our results showed that the endogenous levels were able to support pollen germination. At low concentrations, boron stimulated pollen germination and tube growth. Above $0.02 \%$, boron inhibited pollen germination and tube growth. In the presence of $0.2 \%$ boric acid, the germination percentage was $12.87 \%$, much lower than the $60.25 \%$ germination of the control pollen grains (Figure 2A). The average growth rate of pollen tubes treated with $0.2 \%$ boric acid was distinctly slower than for the control:

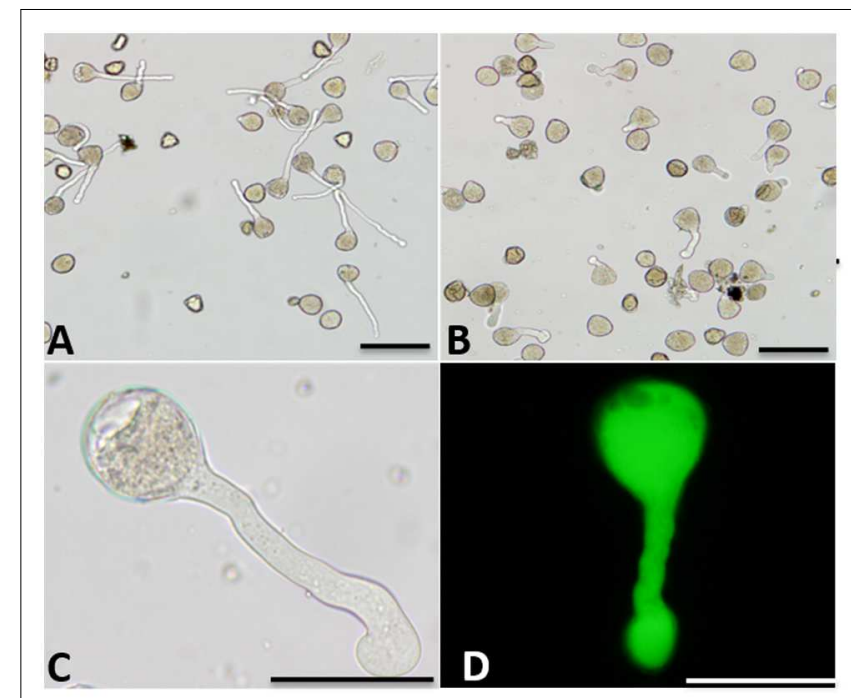

FIGURE 1 | Morphology of Malus domestica pollen tube under boron toxicity. (A) Morphology of a control pollen tube with slender diameter and straight shape. (B) Morphology of a pollen tube treated with $0.2 \%$ boric acid, showing an abnormal tube. (C) Abnormal pollen tubes showing the twisted morphology and swollen tip, respectively. (D) Fluorescein diacetate (FDA) fluorescence indicated viability of the swollen pollen tube. Scale bar: $50 \mu \mathrm{m}$.

the average growth rate of control pollen tubes was $163.7 \mu \mathrm{m} / \mathrm{h}$, whereas the growth rate was only $30.65 \mu \mathrm{m} / \mathrm{h}$ in the presence of $0.2 \%$ boric acid (Figure 2 B).

\section{Boron Toxicity Induced a Decrease in $\left[\mathrm{Ca}^{2+}\right] \mathrm{c}$ Concentration and Disappearance of the $\left[\mathrm{Ca}^{2+}\right] \mathrm{c}$ Gradient}

$\mathrm{Ca}^{2+}$ influx was measured at the extreme apex of the growing pollen tubes using a vibrating electrode technique (non-invasive micro-test technique). The results showed that $\mathrm{Ca}^{2+}$ influx was equal to efflux in the control tube apex at $2 \mathrm{~h}$ after culture. The magnitude of $\mathrm{Ca}^{2+}$ influx at the extreme apex was increased upon $0.2 \%$ boric acid treatment (Figures 3A,B).

Furthermore, $\left[\mathrm{Ca}^{2+}\right] \mathrm{c}$ was detected using Fluo-3/AM in pollen tubes. The control pollen tube tips showed a representative $\left[\mathrm{Ca}^{2+}\right] \mathrm{c}$ gradient within $20-30 \mu \mathrm{m}$ (Figure 3B), while the pollen tubes treated with $0.2 \%$ boric acid showed very weak $\left[\mathrm{Ca}^{2+}\right] \mathrm{c}$ fluorescence in their swollen tips compared to the control, and the $\left[\mathrm{Ca}^{2+}\right] \mathrm{c}$ distribution was totally altered, (Figure 3C, Supplementary Figure S1a) indicating that boron toxicity led to the disappearance of the $\left[\mathrm{Ca}^{2+}\right] \mathrm{c}$ gradient.

\section{Boron Toxicity Varied the Actin Filaments}

Actin filaments take an active part in vesicle trafficking, cell wall construction, and tip growth of pollen tubes (Hao et al., 2013). Thus, the actin cytoskeleton in control and boron toxicitytreated pollen tubes was compared. As observed by LSCM, the actin filaments showed a contiguous bundle through the tube, which was parallel to the growth axis in the control pollen tubes (Figures 4A,A1). However, under boron toxicity, the actin filaments were clearly twisted and condensed. The disrupted 

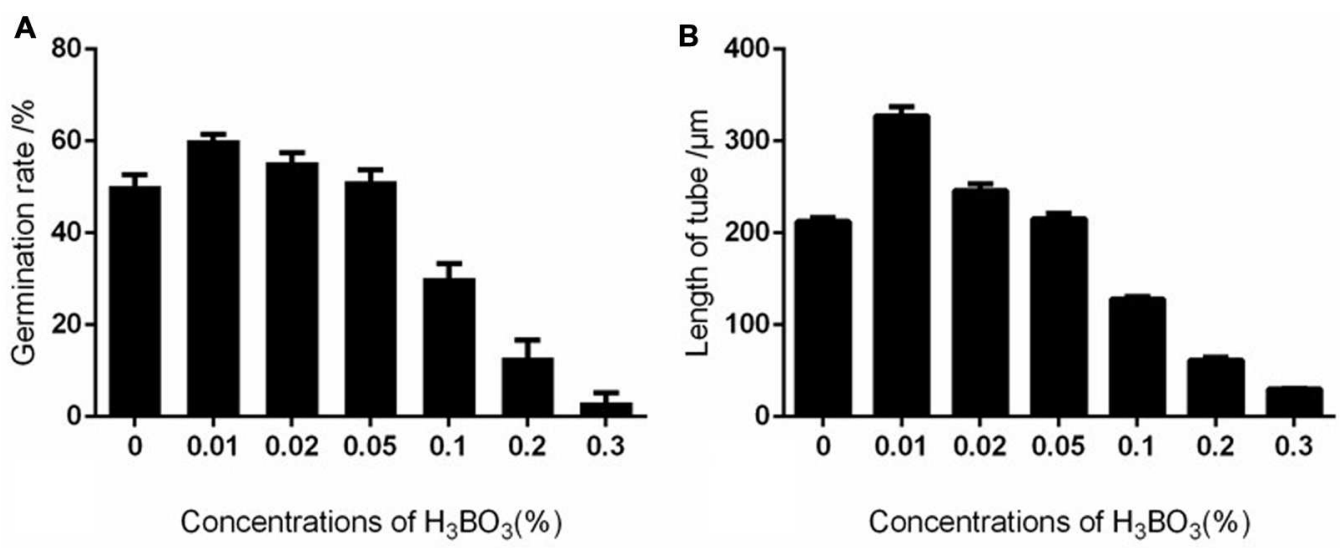

FIGURE 2 | Effect of different concentrations of boric acid on Malus domestica pollen germination and tube length. (A) Effect of different concentrations of boric acid on pollen germination. (B) Effect of different concentrations of boric acid on tube growth.

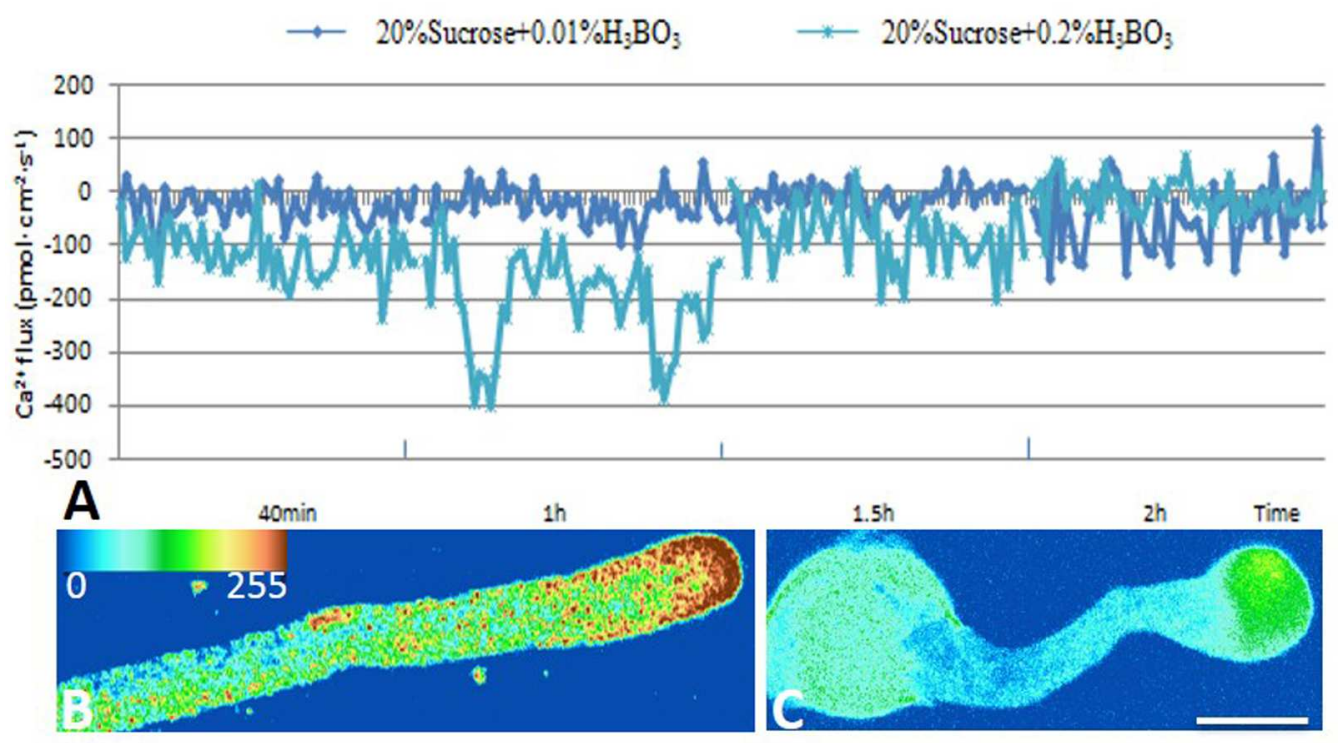

FIGURE 3 | Effect of boron toxicity on the influx of calcium at the apex of Malus domestica pollen tube and $\left[\mathrm{Ca}^{2+}\right] \mathrm{c}$. Bar $=25 \mu \mathrm{m}$. (A) Influx of calcium in the apex of a pollen tube at different time points. The blue line represents the $\mathrm{CK}$, and the green line represents pollen treated with $0.2 \%$ boric acid. (B) The [Ca $\left.{ }^{2+}\right] \mathrm{C}$ gradient at the apex of the control pollen tube. (C) Very weak fluorescence was detected at the apex of the pollen tube under boron toxicity, indicating the disappearance of the $\mathrm{Ca}^{2+}$ gradient.

actin filament fragments accumulated into clusters with a very strong signal in the apical region (Figures 4B,B1, Supplementary Figure S1b).

\section{Effect of Boron Toxicity on Cellulose and Callose Deposition on the Pollen Tube Wall}

As shown in Figure 5, boron toxicity did not alter the distributive pattern and deposition of the cellulose in pollen tube wall (Figures 5A,B,E). Aniline blue staining showed that callose was present evenly along the tube except for the tip in control pollen tubes (Figures 5C,C1). On the contrary, strong fluorescence was observed in the pollen tube tip treated by boron toxicity, suggesting enhanced callose deposition at the tip in response to boron toxicity (Figures 5D,D1,F).

\section{Impact of Boron Toxicity on Pectin and AGP Deposition on Pollen Tube Wall}

In the control pollen tubes, the distribution of JIM5-labeled (deesterified or acid) pectin was relatively uniform, with much at the basal part near the grain and less at the tip (Figures 6A,A1), whereas the localization of JIM7-binding (esterified) pectin was relatively uniform, with stronger fluorescence at the apex of the growing tubes (Figures $\mathbf{6 C}, \mathbf{C 1}, \mathbf{E}$ ). Both types of pectin 


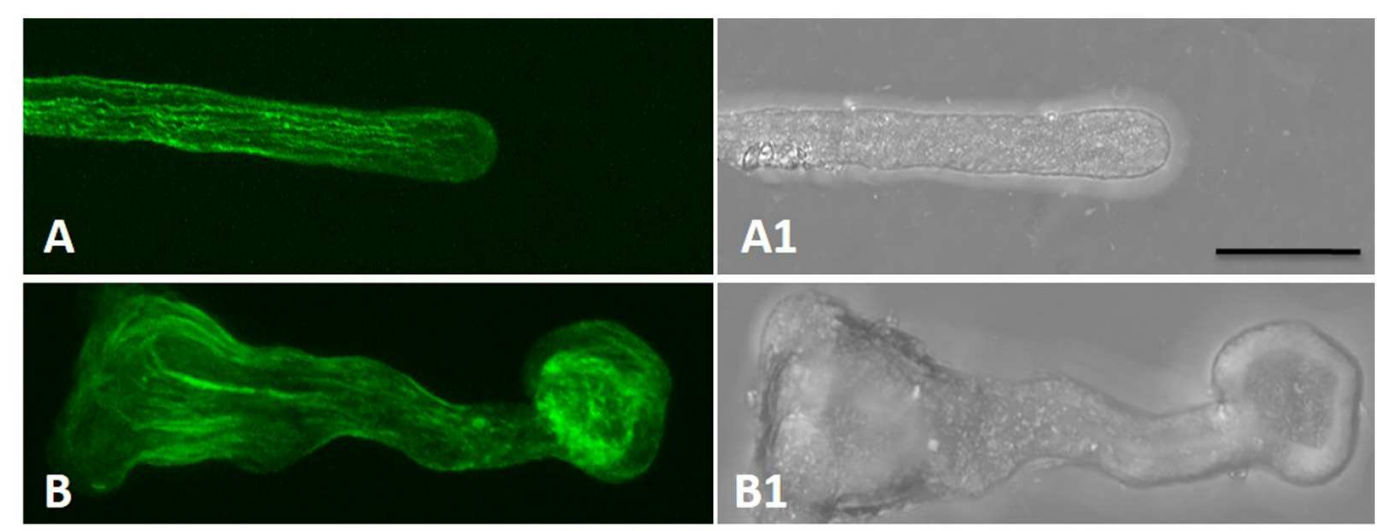

FIGURE 4 | Actin filaments of Malus domestica pollen tube in normal and boron toxicity media. (A) Actin filament paralleled with the pollen tube in the normal culture medium. (A1) Corresponding bright field image of (A). (B) Actin filaments showed serious fracture at the apical part of the pollen tube treated with0.2\% boric acid. (B1) Corresponding bright field image of B. Scale bar: $25 \mu \mathrm{m}$.

showed a polar distribution. By contrast, more de-esterified pectin was detected along the entire tube (Figures 6B,B1) and more esterified pectin was detected on the entire pollen tube under boron toxicity (Figures 6D,D1,F). That is, no obvious polar distribution of pectin was observed in these pollen tubes.

Boron toxicity clearly disrupted the distribution pattern of AGPs. The typical characteristic AGP distribution on the pollen tube wall is a periodic ring-like pattern with a stronger signal in the basal part and weaker signals at the apex (Figures 7A,A1). However, under boron toxicity, the typical pattern disappeared. Instead, continued but irregular deposition was observed (Figures 7B,B1). Quantitative analysis of the fluorescence signal of AGPs in the wall indicated that boron toxicity induced more AGP accumulation in the pole of the tube (Figure 7C).

\section{FTIR Spectroscopy Analysis of Pollen Tube Wall Components}

Representative FTIR spectra gained from the tip domain of control and $0.2 \%$ boric acid-treated pollen tubes are shown in Figure 8. For the control pollen, saturated esters absorbed at $1740 \mathrm{~cm}^{-1}$, amide stretching bands of proteins absorbed at 1638 and $1529 \mathrm{~cm}^{-1}$, carboxylic acid groups absorbed at $1457 \mathrm{~cm}^{-1}$, and carbohydrates absorbed between 1200 and $900 \mathrm{~cm}^{-1}$. In the presence of $0.2 \%$ boric acid, the ester peak at $1738 \mathrm{~cm}^{-1}$ was increased, free acid stretched at $1455 \mathrm{~cm}^{-1}$, and the amide stretching bands of proteins absorbing at 1628 and $1515 \mathrm{~cm}^{-1}$ were increased, indicating that pollen tubes under boron toxicity showed increased esterified pectins, acid pectins and AGPs compared with the values in normal pollen tubes.

\section{DISCUSSION}

Boron toxicity has been report to affect various developmental processes in plants (Nable et al., 1990, 1997; Reid, 2007; Guo et al., 2014). Baluška et al. (2003) reported that interactions between pectins, boron, and the cytoskeleton were important for the assembly of the cell wall-cytoskeleton continuum as well as for its maintenance via signal-mediated processes. So the changes in boron concentrations may cause to a mechanical cascade of signals extending into the cytoplasm via the cell wallplasma membrane-cytoskeleton continuum, with the possible involvement of AGPs (Camacho-Cristóbal et al., 2008). The hypothesis is sustained by the researches that boron deficiency resulted in an varied polymerization pattern of cytoskeletal proteins (Yu et al., 2001, 2003) and in inhibition of the endocytic pathway for the internalization of B-cross-linked RG-II pectins (Yu et al., 2002). Our present work provides novel evidence for this proposal.

\section{Boron Toxicity Induced a Decrease of $\left[\mathrm{Ca}^{2+}\right] \mathrm{c}$ and Disappearance of the $\left[\mathrm{Ca}^{2+}\right] \mathrm{c}$ Gradient}

It has been appreciated that $\mathrm{Ca}^{2+}$ plays a key role in determining the structure and function of the cell wall (Hepler, 2005). The apical wall of normal pollen tube consists almost entirely of pectin, with cellulose and callose being located behind the apex (Ferguson et al., 1998). $\mathrm{Ca}^{2+}$ affected the mechanical properties of the cell wall through cross-linking de-esterified HG of pectin (Peaucelle et al., 2012). As a consequence, when the $\left[\mathrm{Ca}^{2+}\right]$ is lowered sufficiently the pollen tube wall loses its structural integrity and therefore bursts, whereas when $\left[\mathrm{Ca}^{2+}\right]$ is high, the pectin chains will be cross-linked and aggregated, and the wall maximally rigidified (Hepler and Winship, 2010). Picton and Steer (1983) stated that the permissive $\left[\mathrm{Ca}^{2+}\right]$ for pollen tubes extends between $10 \mu \mathrm{M}$ to10 mM. Because $20-30 \%$ of the newly deposited pectin will be de-esterified, there will be always an immediate need for $\mathrm{Ca}^{2+}$ by the growing pollen tube (Hepler and Winship, 2010). $\mathrm{Ca}^{2+}$ has been reported to be involved in the signal transduction pathway of boron deficiency (González-Fontes et al., 2014), which was supported by the reports that boron deficiency increased the 

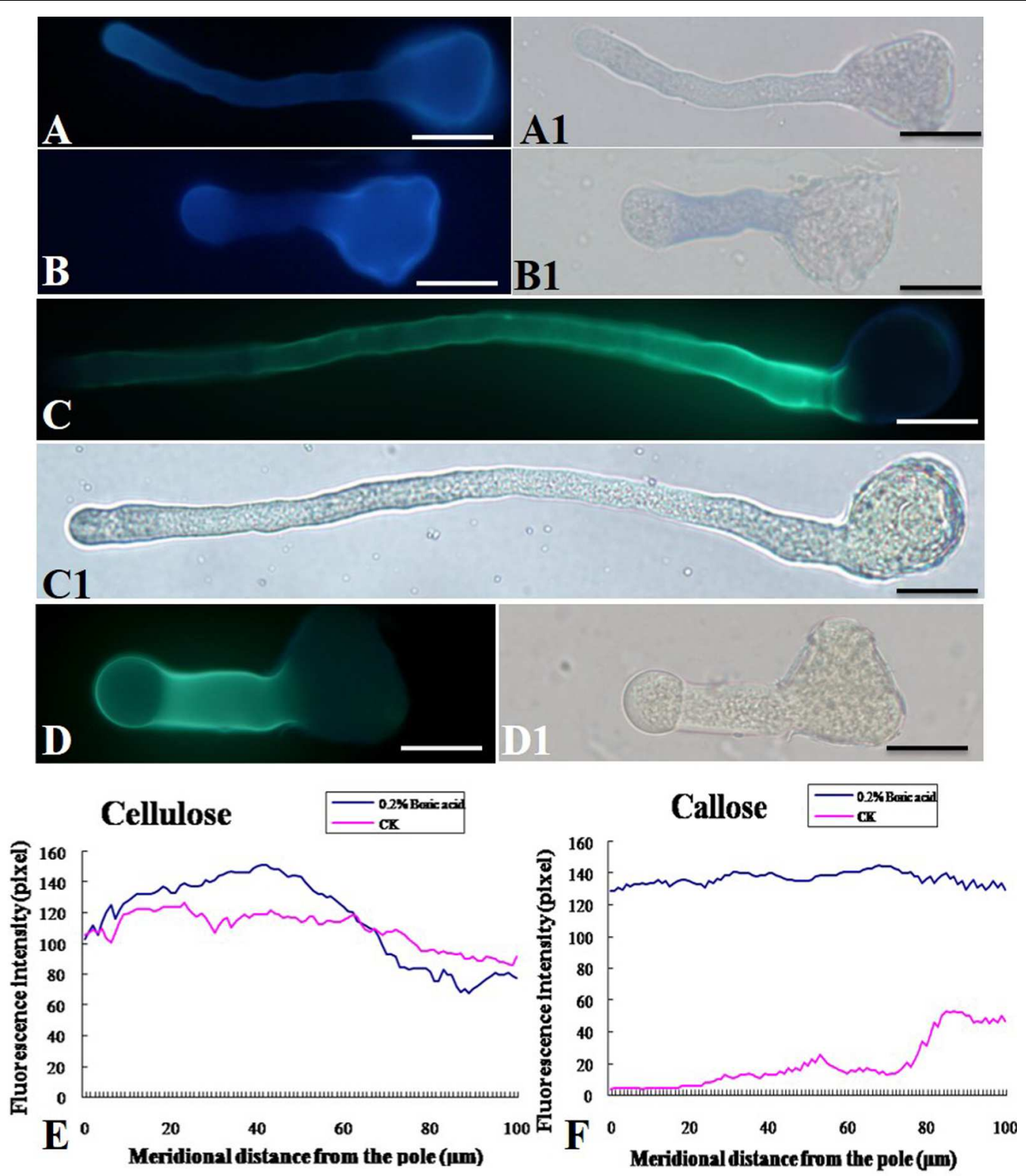

FIGURE 5 | Effect of boron toxicity on the distribution of cellulose and callosein the Malus domestica pollen tube. (A) Cellulose distributed on the whole control pollen tube indicated by fluorescence of calcofluor. (A1) Corresponding bright field image of A. (B) Boron toxicity treated pollen tube showed more cellulose at the pollen tube tip indicated by fluorescence of calcofluor. (B1) Corresponding bright field image of B. (C) Callose was distributed along the entire length of the control pollen tube except the apex. (C1) Corresponding bright field image of C. (D) Strong fluorescence was detected along the entire pollen tube treated by boron toxicity, including the apex, indicating more callose accumulation at the apex under boron toxicity. (D1) Corresponding bright field image of D. (E) Quantitative analysis of the florescent signal of cellulose in the wall of control pollen tubes (CK, pink line) and tubes under boron toxicity (0.2\% boric acid, blue line).

(F) Quantitative analysis of the fluorescent signal of callose in the wall of control pollen tubes (CK, pink line) and tubes under boron toxicity (0.2\% boric acid, blue line). Scale bar: $25 \mu \mathrm{m}$.

levels of cytosolic $\mathrm{Ca}^{2+}$ in tobacco BY-2 cells (Koshiba et al., 2010) and Arabidopsis thaliana roots (Quiles-Pando et al., 2013).

In the present study, we revealed that boron toxicity induced a decrease in $\left[\mathrm{Ca}^{2+}\right] \mathrm{c}$ concentration and a disappearance of the $\left[\mathrm{Ca}^{2+}\right] \mathrm{c}$ gradient, suggesting the sensitive and critical role of $\mathrm{Ca}^{2+}$ in boron signaling in the proposed mechanical cascade of signals which extended from cell wall to the cytoplasm via the cell wall-plasma membrane-cytoskeleton continuum (CamachoCristóbal et al., 2008). Calcium is likely a major element in transmitting boron signals and modulating cytoplasmic activities. We speculate that excessive boron first binds to pectin in the wall of the pollen tube and provides many more binding sites for calcium, which results in a $\left[\mathrm{Ca}^{2+}\right] \mathrm{c}$ decrease and the disappearance of the calcium gradient in the tip of the pollen tube, resulting in irregular pollen tube growth. Although 

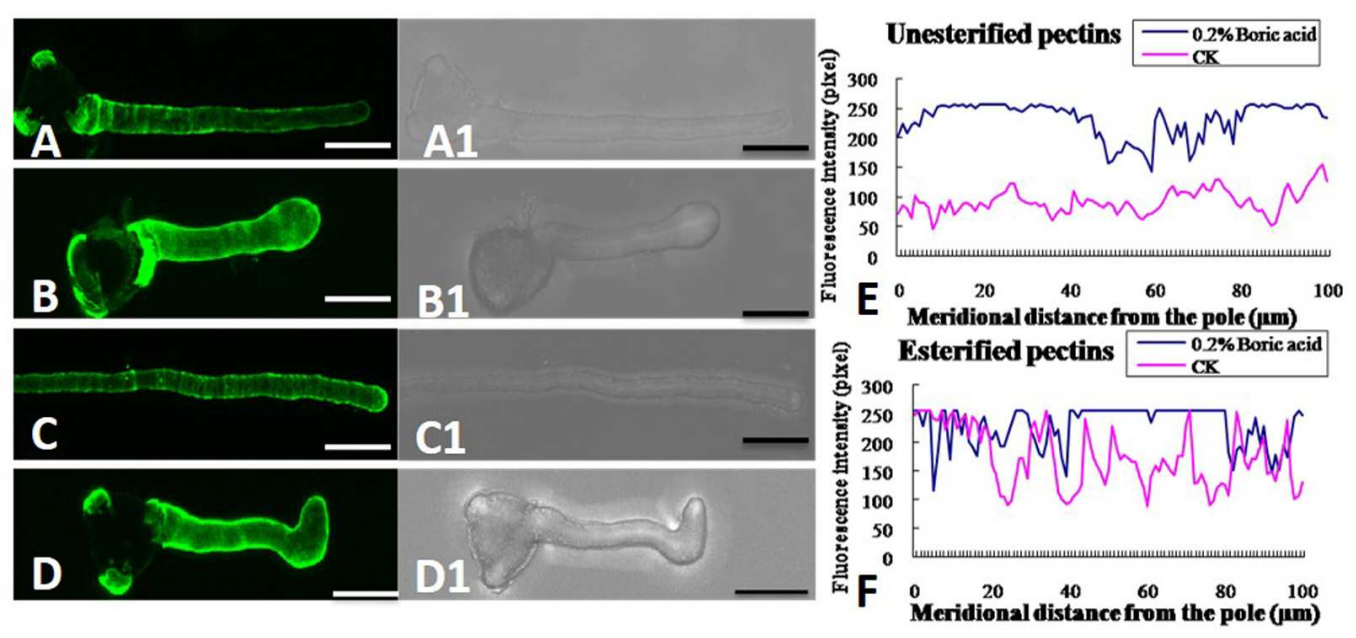

FIGURE 6 | Effect of boron toxicity on the distribution of acid and esterified pectins, respectively. (A) Fluorescence by JIM5 labeling of control pollen tubes with much acid pectin at the basal part and less in the apex. (A1) Corresponding bright field image of a. (B) Fluorescence indicated more acid pectins in the apex of the boron toxicity-treated pollen tube. (B1) Corresponding bright field image of b. (C) Fluorescence from JIM7 labeling of control pollen tube with much esterified pectin in the apex. (C1) Corresponding bright field image of c. (D) Fluorescence was observed evenly along the tube after antibody JIM7 labeling of pollen tubes in the presence of boron toxicity. (D1) Corresponding bright field image of d. (E) Quantitative analysis of the fluorescence signal of acid pectins in the wall of control pollen tubes (CK, pink line) and tubes under boron toxicity ( $0.2 \%$ boric acid, blue line). (F) Quantitative analysis of the fluorescence signal of esterified pectins in the wall of the control pollen tubes (CK, pink line) and tubes under boron toxicity $(0.2 \%$ boric acid, blue line). Scale bar: $25 \mu \mathrm{m}$.

more evidence is needed to support this proposal, our results indicated that calcium might be involved in the responses to boron toxicity.

\section{Boron Toxicity Disturbed the Actin Filaments}

Boron deficiency induced alteration of cytoskeleton biosynthesis (Yu et al., 2001, 2002), suggesting that a linkage between boron and cytoskeleton may exist. Previous evidence indicates that actin filaments play an essential role in the transport of secretory vesicles and pollen tube growth (Cárdenas et al., 2008; Fu, 2015; Qu et al., 2015). In normal pollen tubes, actin filaments are reported to be arrayed in bundles and extend the subapical region (Shi and Yang, 2010). It was reported that there exists crosstalk between calcium signaling and cytoskeleton in the pollen tube, while $\mathrm{Ca}^{2+}$ is a central factor controlling the transition from G-actin in the tube apex to the F-actin cables in the shank (Shi and Yang, 2010). These results suggest that $\mathrm{Ca}^{2+}$ is critical for the actin organization in pollen tubes.

In the present research, we have revealed that actin organization is sensitive to boron toxicity. Both the specialized structure and distribution were clearly disturbed in pollen tubes under boron toxicity. This abnormal appearance of actin organization was coupled with decreased $\left[\mathrm{Ca}^{2+}\right] \mathrm{c}$ and the disappearance of the $\left[\mathrm{Ca}^{2+}\right] c$ gradient in pollen tubes under boron toxicity. Based on the previous findings noted above, it is reasonable to speculate that actin organization abnormality might result from boron toxicity-induced low $\left[\mathrm{Ca}^{2+}\right] \mathrm{c}$. It is likely that boron toxicity signaling is mediated by calcium dynamics to achieve the cytoplasmic response.

\section{Boron Toxicity Altered the Deposition of Pollen Tube Wall Components}

Boron toxicity affects the morphology of pollen tube, thus we want to know whether the tube wall composition was affected by boron toxicity. Results showed that cellulose was present throughout the pollen tube wall under normal conditions and under boron toxicity. Boron toxicity showed no obvious effect on the cellulose deposition of the pollen tube. Callose can be synthesized in the normal pollen tube walls (Qin et al., 2012). In addition, callose is distributed at the tips of abnormal pollen tubes (Hao et al., 2013). Our results showed that boron toxicity altered the deposition pattern of the callose in the pollen tube walls of Malus domestica. In the control pollen tube, callose was detected along the entire pollen tube except for the tip, but in the presence of boron toxicity, callose was distributed along the entire tube including the tip.

Beside cellulose and callose, pectin is an important composition of the pollen tube wall. Pectin is secreted mainly as methoxy-esters, and later de-esterified t by the enzyme pectin methyl esterase (PME) (Bosch and Hepler, 2005; Peaucelle et al., 2012). Plant cell wall also contains essential minerals including calcium and boron, which are necessary for formation of networks of pectic polysaccharides in cell walls. The extent and strength of $\mathrm{Ca}^{2+}$ cross-linking depend on the acidic residue of the de-esterified pectins (Hepler and Winship, 2010). Research by Fang et al. (2008) illustrated that pectin associates with carboxyl moieties which participate in binding with free $\mathrm{Ca}^{2+}$ to form plastic gels. Ngouémazong et al. (2012) reported that at high $\left[\mathrm{Ca}^{2+}\right]$, with a low degree of methoxylation, pectins reach maximum strength. According to the previous studies, pollen tube growth is speculated to depend on a balance between the 

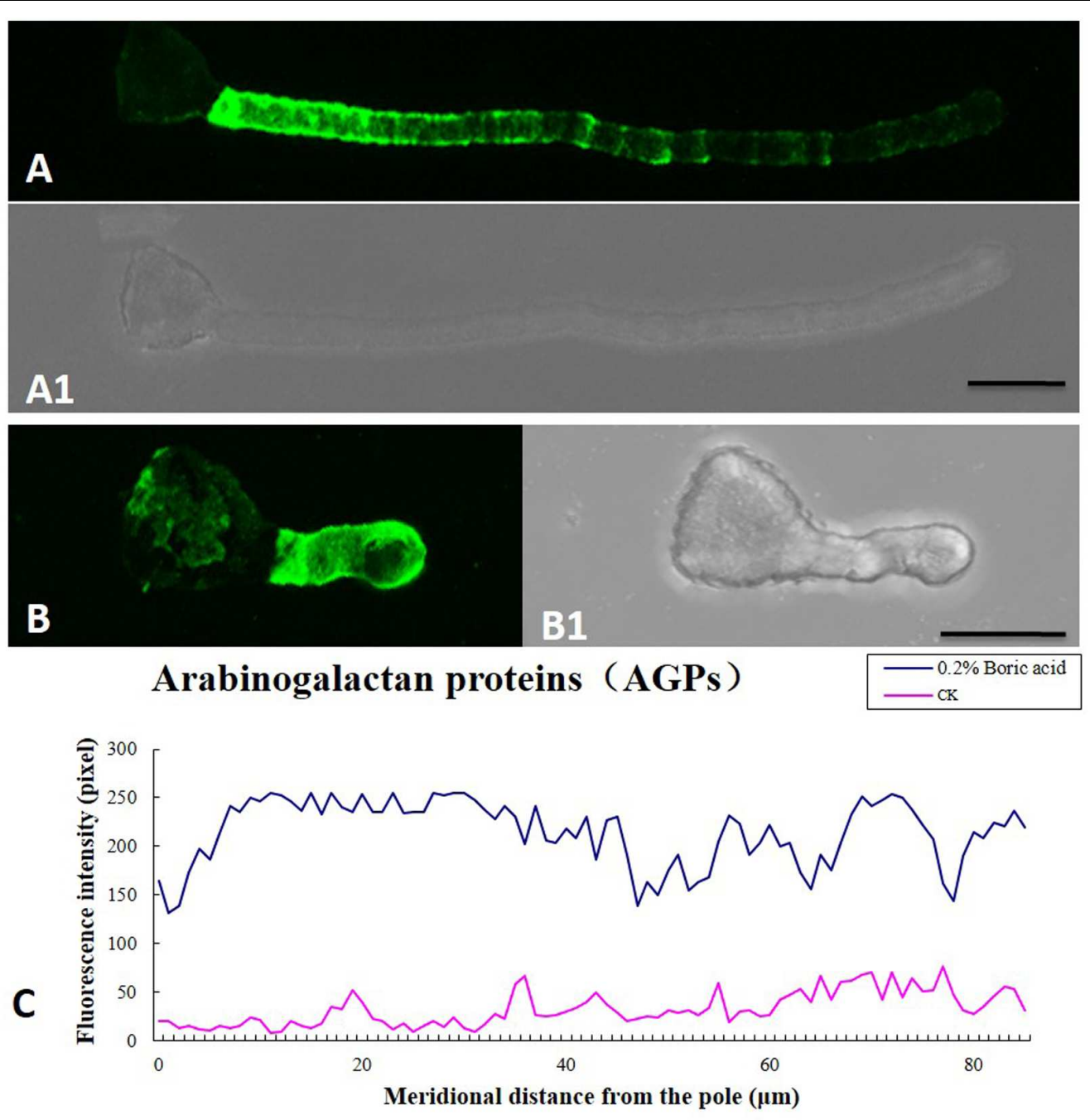

FIGURE 7 | Influence of boron toxicity on the distribution of arabinogalactan proteins (AGPs) in Malus domestica pollen tubes. (A) Fluorescence after antibody LM2 labeling of pollen tubes cultured in normal medium, indicating more AGPs in the basal part and decreasing levels from the base to the pollen tip. (A1) Corresponding bright field image of (A). (B) Fluorescence was observed throughout the entire tube; note the irregular distribution. (B1) Corresponding bright field image of (B). (C) Quantitative analysis of fluorescence signal of AGPs in the wall of control pollen tubes (CK, pink line) and boron toxicity-treated tubes ( $0.2 \%$ boric acid, blue line). Scale bar: $25 \mu \mathrm{m}$.

number of available acidic residues and the $\left[\mathrm{Ca}^{2+}\right]$. That is too few acidic groups or too little $\mathrm{Ca}^{2+}$ will lead to the pollen tube burst, but too many acidic groups and/or too much $\mathrm{Ca}^{2+}$ will result in overly cross-linked wall and therefore pollen tube can't extend (Hepler and Winship, 2010). Our immunolabeling results showed that in the boron toxicity-treated pollen tube, there was more acidic pectin, which could create more binding sites for calcium and thus result in less calcium ion in the cytoplast. Therefore, the ratio of de-esterified pectin to esterified pectin plays a critical role in the adjustment of the cytoplasmic calcium level and in the transmission of boron toxicity-induced effects on pollen tube growth.

Arabinogalactan proteins are proteins which exist in plant and distribute through different developmental stages (Pereira et al., 2014). AGPs can interact with pectins or other cell wall-localized proteins (Baldwin et al., 1993; Showalter, 2001). Recent researches have enhanced our understanding of AGP's role in plant (Lamport and Várnai, 2013; Lamport et al., 2014). AGPs may play an essential role in the boron deficiency signal transduction by binding $\mathrm{Ca}^{2+}$ (GonzálezFontes et al., 2014). In the present study, AGPs were deposited by LM2, indicating that boron toxicity caused AGPs to accumulate throughout the pollen tube except the basal part near the grain, instead of the characteristic periodic ring-like deposits with less signal at the tip. Boron toxicity changed the distribution pattern and quantity of AGPs, which may interlink with calcium and actin alteration. More AGPs might bind to more calcium and result in low $\left[\mathrm{Ca}^{2+}\right] \mathrm{c}$. These findings indicated that boron toxicity induced reconstruct of tip cell wall components, resulting in cell 


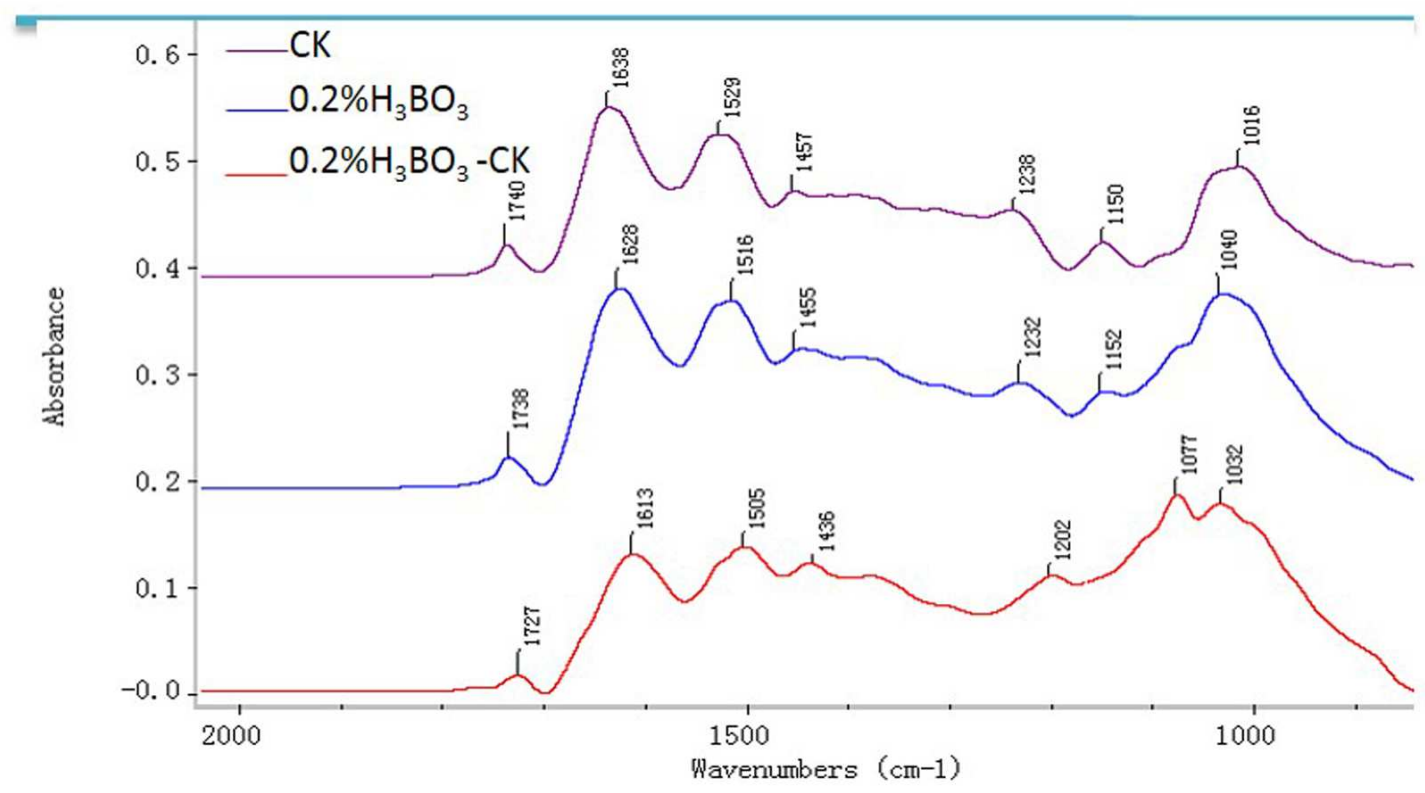

FIGURE 8 | Fourier-transform infrared analysis spectra from the tip regions of Malus domestica pollen tubes (control pollen tube: CK; pink), pollen tubes treated with $0.2 \%$ boric acid medium (blue, $0.2 \% \mathrm{H}_{3} \mathrm{BO}_{3}$ ) and the FTIR differential spectrum (red) generated by digital subtraction of the pink spectra (CK) from the blue spectra $\left(0.2 \% \mathrm{H}_{3} \mathrm{BO}_{3}\right)$.

wall rigidity/extensibility changes and subsequent slowing and cessation of growth.

It can be expected that boron toxicity alters the cell wall structure, and a rapid change in the mechanical strength of the cell wall occurs. This effect triggers a mechanical cascade of signals through the cell wall-plasma membrane-cytoskeleton continuum, in which AGPs most likely take an active part (Goldbach and Wimmer, 2007). This expectation agrees with the structural modification of the cell wall pectin and cytoskeleton under boron toxicity in this research.

Boron toxicity is an important agricultural problem that limits crop productivity, however, under boron stress condition, how much boron could accumulated in style and directly regulate pollen tube growth remains unknown. Therefore, in vitro test the influence of the high boron on pollen tube growth will provide useful clue to understand possible response of pollen tube to the stress.

In the low rainfall and on highly alkaline and saline soil where the rate of boron is over $2.0 \mathrm{mg} / \mathrm{L}$, there is boron pollution and consequently decreases in production and defect in the products can be seen (Ozturk et al., 2010). When boron is present at high concentrations in the soil or ground water, plant growth, and reproduction can be affected by boron toxicity (Roessner et al., 2006). So boron toxicity has been recognized as an important problem limiting crop production. Following long-term exposure to high $\mathrm{B}$ concentrations, overall vegetative plant growth is retarded and this leads to either a reduction in or a complete lack of seed set (Roessner et al., 2006).

Application of boron fertilizer in soil and boron foliar application appear worthwhile in the field. Both of the methods increased the boron concentration in various parts of the plant
(Asad et al., 2003). There are no data on boron concentration in style and how much boron pollen tube could absorb from style so far. However, based on the previous study mentioned above, the concentration of boron in style increases if the plant grows under high boron. Whether the boron concentrations used in the present study is similar to the in vivo values need further research.

Our in vitro test illustrated that $0.2 \%$ boron inhibited Malus domestica pollen germination and arrested pollen tube growth. Based on this, if boron foliar application or boron in the soil at high concentrations leads to similar boron concentration in style, it will be harmful to pollen tube growth.

In brief, our investigation of the effects of boron toxicity on Malus domestica pollen tubes provides an extensive understanding of the role of boron in the polarized tip growth of pollen tubes. We found that boron toxicity decreases $\left[\mathrm{Ca}^{2+}\right] \mathrm{c}$, inducing the disappearance of the $\left[\mathrm{Ca}^{2+}\right] \mathrm{c}$ gradient and altering actin filament organization. The distorted actin filament may disturb transport of the wall precursor to the pollen tube wall, resulting in defects in cell wall construction and variations in pollen tube tip growth. This research provides new insights into the boron function in pollen tube growth and valuable evidence for the previous proposal that boron may lead to a mechanical cascade of signals from the wall to the cytoplasm through the cell wall-plasma membrane-cytoskeleton continuum.

\section{AUTHOR CONTRIBUTIONS}

The authors have made the following declarations regarding their contributions: Conceived and designed the experiments: KF. Performed the experiments: WZ, KF. Analyzed the data: KF, 
WZ, YX, QZ, LY, and LQ. Contributed to the writing of the manuscript: KF, WZ, YX, QC, and LQ.

\section{ACKNOWLEDGMENTS}

This work was supported by the National Natural Science Foundation of China (31270719), the Importation and Development of High-Caliber Talents Project of Beijing Municipal Institutions (CIT\&TCD201304095) and the Project of Construction of Innovative Teams and Teacher Career Development for Universities and Colleges under Beijing

\section{REFERENCES}

Aquea, F., Federici, F., Moscoso, C., Vega, A., Jullian, P., Haseloff, J., et al. (2012). A molecular framework for the inhibition of Arabidopsis root growth in response to boron stress. Plant Cell Environ. 35, 719-734. doi: 10.1111/j.13653040.2011.02446.x

Asad, A., Blamey, F. P. C., and Edwards, D. G. (2003). Effect of Boron foliar applications on vegetative and reproductive growth of sunflower. Ann. Bot. 92, 565-570. doi: 10.1093/aob/mcg179

Baldwin, T. C., McCann, M. C., and Roberts, K. (1993). A novel hydroxyproline deficient arabinogalactan protein secreted by suspension-cultured cells of Daucus carota. (purification and partial characterization). Plant Physiol. 103, 115-123. doi: 10.1104/pp.103.1.115

Baluška, F., Šamaj, J., Wojtaszek, P., Volkmann, D., and Menzel, D. (2003). Cytoskeleton - plasma membrane - cell wall continuum in plants: emerging links revisited. Plant Physiol. 133, 482-491. doi: 10.1104/pp.103.027250

Blevins, D. G., and Lukaszewski, K. (1998). Boron in plant structure and function. Annu. Rev. Plant Physiol. Plant Mol. Biol 49, 481-500. doi: 10.1146/annurev.arplant.49.1.481

Bosch, M., and Hepler, P. K. (2005). Pectin methylesterases and pectin dynamics in pollen tubes. Plant Cell 17, 3219-3226. doi: 10.1105/tpc.105.037473

Bou, D. F., and Geitmann, A. (2011). Actin is involved in pollen tube tropism through redefining the spatial targeting of secretory vesicles. Traffic 12, 15371551. doi: $10.1111 /$ j.1600-0854.2011.01256.x

Braccini, I., and Perez, S. (2001). Molecular basis of Ca2+ induced gelation in alginates and pectins: the egg-box model revisited. Biomacromolecules 2, 1089-1096. doi: 10.1021/bm010008g

Camacho-Cristóbal, J. J., Rexach, J., and González-Fontes, A. (2008). Boron in Plants: deficiency and toxicity. J. Int. Plant Biol. 50, 1247-1255. doi: 10.1111/j.1744-7909.2008.00742.x

Cañon, P., Aquea, F., Rodríguez-Hoces de la Guardia, A., and ArceJohnson, P. (2013). Functional characterization of Citrus macrophylla BOR1 as a boron transporter. Physiol. Plant 149, 329-339. doi: 10.1111/ppl. 12037

Cárdenas, L., Lovy-Wheeler, A., Kunkel, J. G., and Hepler, P. K. (2008). Pollen tube growth oscillations and intracellular calcium levels are reversibly modulated by actin polymerization. Plant Physiol. 146, 1611-1621. doi: 10.1104/pp.107.113035

Cervilla, L. M., Blasco, B., Ríos, J. J., Romero, L., and Ruiz, J. M. (2007). Oxidative stress and antioxidants in tomato (Solanum lycopersicum) plants subjected to boron toxicity. Ann. Bot. 100, 747-756. doi: 10.1093/aob/ mcm156

Chebli, Y., Pujol, L., Shojaeifard, A., Brouwer, I., van Loon, J. J., and Geitmann, A. (2013). Cell wall assembly and intracellular trafficking in plant cells are directly affected by changes in the magnitude of gravitational acceleration. PLOS ONE 8:e58246. doi: 10.1371/journal.pone.0058246

Chen, T., Teng, N. J., Wu, X. Q., Wang, Y. H., Tang, W., Šamaj, J., et al. (2007). Disruption of actin filaments by latrunculin B affects cell wall construction in Picea meyeri pollen tube by disturbing vesicle trafficking. Plant Cell Physiol. 48, 19-30. doi: 10.1093/pcp/pcl036

Dafni, A. (2000). A new procedure to assess pollen viability. Sex. Plant Reprod. 12, 241-244. doi: $10.1007 /$ s004970050008
Municipality (IDHT20140509). The authors thank AE for English editing.

\section{SUPPLEMENTARY MATERIAL}

The Supplementary Material for this article can be found online at: http://journal.frontiersin.org/article/10.3389/fpls.2016.00208

FIGURE S1 | (a) Weak fluorescence was detected at the apex of the pollen tube under boron toxicity for $1.5 \mathrm{~h}$, no $\mathrm{Ca}^{2+}$ gradient was visible. (b) The actin deposition varied upon treatment with high boron for $1.5 \mathrm{~h}$.

Dickinson, D. B. (1978). Influence of borate and pentaerythritol concentration on germination and tube growth of Lilium longiflorum pollen. J. Am. Soc. Hortic. Sci. 103, 263-269.

Dumont, M., Lehner, A., Bouton, S., Kiefer-Meyer, M. C., Voxeur, A., Pelloux, J., et al. (2014). The cell wall pectic polymer rhamnogalacturonanII is required for proper pollen tube elongation: implications of a putative sialyltransferase-like protein. Ann. Bot. 114, 1177-1188. doi: 10.1093/aob/ mcu093

Fang, Y., Al-Assaf, S., Phillips, G. O., Nishinari, K., Funami, T., and Williams, P. A. (2008). Binding behavior of calcium to polyuronates: comparison of pectin with alginate. Carbohydr. Polym. 72, 334-341. doi: 10.1016/j.carbpol.2007. 08.021

Ferguson, C., Teeri, T. T., Siika-aho, M., Read, S. M., and Bacic, A. (1998). Location of cellulose and callose in pollen tubes and grains of Nicotiana tabacum. Planta 206, 452-460. doi: 10.1007/s004250050421

Franklin-Tong, V. E. (1999). Signaling and the modulation of pollen tube growth. Plant Cell 11, 727-738. doi: 10.1105/tpc.11.4.727

Fu, Y. (2015). The cytoskeleton in the pollen tube. Curr. Opin. Plant Biol. 6, 111-119. doi: 10.1016/j.pbi.2015.10.004

Funakawa, H., and Miwa, K. (2015). Synthesis of borate cross-linked rhamnogalacturonan II. Front. Plant Sci. 6:223. doi: 10.3389/fpls.2015.00223

Gao, S., Wang, J. L., Wang, J. J., Cao, Q. Q., Qin, L., and Fang, K. F. (2014). Comparison analysis of mineral elements composition on four pollens. J. Agricul 4, 77-80.

Geitmann, A. (1999). "The rheological properties of the pollen tube cell wall," in Fertilization in Higher Plants, eds M. Cresti, G. Cai, and A. Moscatelli (Berlin: Springer), 283-297.

Goldbach, H. E., and Wimmer, M. A. (2007). Boron in plants and animals: is there a role beyond cell-wall structure? J. Plant Nutr. Soil Sci. 170, 39-48. doi: 10.1002/jpln.200625161

González-Fontes, A., Navarro-Gochicoa, M. T., Camacho-Cristóbal, J. J., HerreraRodríguez, M. B., Quiles-Pando, C., and Rexach, J. (2014). Is $\mathrm{Ca}^{2+}$ involved in the signal transduction pathway of boron deficiency? New hypotheses for sensing boron deprivation. Plant Sci. 217-218, 135-139. doi: 10.1016/j.plantsci.2013.12.011

Gunes, A., Soylemezoglu, G., Inal, A., Bagci, E. G., Coban, S., and Sahin, O. (2006). Antioxidant and stomatal responses of grapevine (Vitis vinifera L.) to boron toxicity. Sci. Horticul. 110, 279-284. doi: 10.1016/j.scienta.2006. 07.014

Guo, P., Qi, Y. P., Yang, L. T., Ye, X., Jiang, H. X., Huang, J. H., et al. (2014). CDNA-AFLP analysis reveals the adaptive responses of citrus to long-term boron-stress. BMC Plant Biol. 14:284. doi: 10.1186/s12870-014-0284-5

Hao, H. Q., Chen, T., Fan, L., Li, R. L., and Wang, X. H. (2013). 2, 6dichlorobenzonitrile causes multiple effects on pollen tube growth beyond altering cellulose synthesis in Pinus bungeana Zucc. PLoS ONE 8:e76660. doi: 10.1371/journal.pone.0076660

Hasegawa, Y., Nakamura, S., Kakizoe, S., Sato, M., and Nakamura, N. (1998). Immunocytochemical and chemical analyses of Golgi vesicles isolated from the germinated pollen of Camellia japonica. J. Plant Res. 111, 421-429. doi: 10.1023/A:1010662911148

Hepler, P. K. (2005). Calcium: a central regulator of plant growth and development. Plant Cell 17, 2142-2155. doi: 10.1105/tpc.105.032508 
Hepler, P. K., and Winship, L. J. (2010). Calcium at the cell wall-cytoplast interface. J. Int. Plant Biol. 52, 147-160. doi: 10.1111/j.1744-7909.2010. 00923.x

Holdaway-Clarke, T. L., and Hepler, P. K. (2003). Control of pollen tube growth: role of ion gradients and fluxes. New Phytol. 159, 539-563. doi: 10.1016/j.bbamcr.2012.10.009

Karabal, E., Yücel, M., and Ökte, H. A. (2003). Antioxidants responses of tolerant and sensitive barley cultivars to boron toxicity. Plant Sci. 164, 925-933. doi: 10.1016/S0168-9452(03)00067-0

Keles, Y., Öncel, I., and Yenice, N. (2004). Relationship between boron content and antioxidant compounds in Citrus leaves taken from fields with different water source. Plant Soil 265, 345-353. doi: 10.1007/s11104-005-0646-8

Ketelaar, T., Galway, M. E., Mulder, B. M., and Emons, A. M. (2008). Rates of exocytosis and endocytosis in Arabidopsis root hairs and pollen tubes. J. Microsci. 231, 265-273. doi: 10.1111/j.1365-2818.2008. 02031.x

Koshiba, T., Kobayashi, M., Ishihara, A., and Matoh, T. (2010). Boron nutrition of cultured tobacco BY-2 cells. VI. Calcium is involved in early responses to boron deprivation. Plant Cell Physiol. 251, 323-327. doi: 10.1093/pcp/ pcp179

Lamport, D. T. A., and Várnai, P. (2013). Periplasmic arabinogalactan glycoproteins act as a calcium capacitor that regulates plant growth and development. New Phytol. 197, 58-64. doi: 10.1111/nph.12005

Lamport, D. T. A., Varnai, P., and Seal, C. E. (2014). Back to the future with the AGP-Ca ${ }^{2+}$ flux capacitor. Ann. Bot. 114, 1069-1085. doi: 10.1093/aob/ mcu161

Landi, M., Remorini, D., Pardossi, A., and Guidi, L. (2013). Boron excess affects photosynthesis and antioxidant apparatus of greenhouse Cucurbita pepo and Cucumis sativus. J. Plant Res. 126, 775-786. doi: 10.1007/s10265-0130575-1

Lazzaro, M. D., Donohue, J. M., and Soodavar, F. M. (2003). Disruption of cellulose synthesis by isoxaben causes tip swelling and disorganizes cortical microtubules in elongating conifer pollen tubes. Protoplasma 220, 201-207. doi: 10.1007/s00709-002-0042-7

Li, Y. Q., Mareck, A., Faleri, C., Moscatelli, A., Liu, Q., and Cresti, M. (2002). Detection and localization of pectin methylesterase isoforms in pollen tubes of Nicotiana tabacum L. Planta 214, 734-740. doi: 10.1007/s0042501 00664

Li, Y. Q., Zhang, H. Q., Pierson, E. S., Huang, F. Y., Linskens, H. F., Hepler, P. K., et al. (1996). Enforced growth-rate fluctuation causes pectin ring formation in the cell wall of Lilium longiflorum pollen tubes. Planta 200, 41-49. doi: 10.1007/BF00196647

Loomis, W. D., and Durst, R. W. (1992). Chemistry and biology of boron. Biofactors $3,229-239$.

Miwa, K., Takano, J., Omori, H., Seki, M., Shinozaki, K., and Fujiwara, T. (2007). Plants tolerant of high boron levels. Science 318:1417. doi: $10.1126 /$ science. 1146634

Molassiotis, A., Sotiropoulos, T. E., Tanou, G., Diamantidis, G., and Therios, I. (2006). Boron induced oxidative damage and antioxidant and nucleolytic responses in shoot tips culture of the apple rootstock EM9 (Malus domestica Borkh). Environ. Exp. Bot. 56, 54-62. doi: 10.1016/j.envexpbot.2005. 01.002

Moscatelli, A., and Idilli, A. I. (2009). Pollen tube growth: a delicate equilibrium between secretory and endocytic pathways. J. Integr. Plant Biol. 51, 727-739. doi: 10.1111/j.1744-7909.2009.00842.x

Nable, O. R., Bañuelos, G. S., and Paull, J. G. (1997). Boron toxicity. Plant Soil 193, 181-198. doi: 10.1023/A:1004272227886

Nable, O. R., Lance, R. C. M., and Cartwright, B. (1990). Uptake of boron and silicon by barley genotypes with differing susceptibilities to boron toxicity. Ann. Bot. (Lond) 66, 83-90.

Ngouémazong, D. E., Jolie, R. P., Cardinaels, R., Fraeye, I., Van Loey, A., Moldenaers, P., et al. (2012). Stiffness of $\mathrm{Ca}^{2+}$-pectin gels: combined effects of degree and pattern of methylesterification for various $\mathrm{Ca}^{2+}$ concentrations. Carbohydr. Res. 348, 69-76. doi: 10.1016/j.carres.2011.11.011

Obermeyer, G., Kriechbaumer, R., Strasser, D., Maschessning, A., and Bentrup, F. W. (1996). Boric acid stimulates the plasma membrane $\mathrm{H}^{+}$-ATPase of ungerminated lily pollen grains. Physiol. Plant 98, 281-290. doi: 10.1034/j.13993054.1996.980209.x
Ozturk, M., Sakcali, S., Gucel, S., and Rombuloglu, H. (2010). "Boron and plants," in Plant Adaptation and Phytoremediation, eds M. Ashrat, M. Ozturk, and M. S. A. Ahmad (Berlin: Springer), 275-311.

Pang, Y., Li, L., Ren, F., Lu, P., Wei, P., Cai, J., et al. (2010). Overexpression of the tonoplast aquaporin AtTIP5; 1 conferred tolerance to boron toxicity in Arabidopsis. J. Genet. Genomics 37, 389-397. doi: 10.1016/S16738527(09)60057-6

Paull, J. G., Nable, R. O., and Rathjen, A. J. (1992). Physiological and genetic control of the tolerance of wheat to high concentrations of boron and implications for plant breeding. Plant Soil 146, 251-260. doi: 10.1007/BF000 12019

Peaucelle, A., Braybrook, S., and Höfte, H. (2012). Cell wall mechanics and growth control in plants: the role of pectins revisited. Front. Plant Sci. 3:121. doi: 10.3389/fpls.2012.00121

Pereira, A. M., Masiero, S., Nobre, M. S., Costa, M. L., Solís, M. T., Testillano, P. S., et al. (2014). Differential expression patterns of arabinogalactan proteins in Arabidopsis thaliana reproductive tissues. J. Exp. Bot. 65, 5459-5471. doi: $10.1093 / \mathrm{jxb} / \mathrm{eru} 300$

Pérez-Castro, R., Kasai, K., Gainza-Cortés, F., Ruiz-Lara, S., Casaretto, J. A., Peña-Cortés, H., et al. (2012). VvBOR1, the grapevine ortholog of AtBOR1, encodes an efflux boron transporter that is differentially expressed throughout reproductive development of Vitis vinifera L. Plant Cell Physiol. 53, 485-494. doi: 10.1093/pcp/pcs001

Picton, J. M., and Steer, M. W. (1983). Evidence for the role of $\mathrm{Ca}^{2+}$ ions in tip extension in pollen tubes. Protoplasma 115, 11-17. doi: 10.1007/BF012 93575

Qin, P., Ting, D., Shieh, A., and McCormick, S. (2012). Callose plug deposition patterns vary in pollen tubes of Arabidopsis thaliana ecotypes and tomato species. BMC Plant Biol. 12:178. doi: 10.1186/1471-2229-12-178

Qu, X. L., Jiang, Y. X., Chang, M., Liu, X. N., Zhang, R. H., and Huang, S. J. (2015). Organization and regulation of the actin cytoskeleton in the pollen tube. Front. Plant Sci. 5:786. doi: 10.3389/fpls.2014.00786

Quiles-Pando, C., Rexach, J., Navarro-Gochicoa, M. T., Camacho-Cristóbal, J. J., Herrera-Rodríguez, M. B., and González-Fontes, A. (2013). Boron deficiency increases the levels of cytosolic $\mathrm{Ca}^{2+}$ and expression of $\mathrm{Ca}^{2+}$-related genes in Arabidopsis thaliana roots. Plant Physiol. Biochem. 65, 55-60. doi: 10.1016/j.plaphy.2013.01.004

Reid, R. (2007). Identification of boron transporter genes likely to be responsible for tolerance to boron toxicity in wheat and barley. Plant Cell Physiol. 48, 1673-1678. doi: 10.1093/pcp/pcm159

Roessner, U., Patterson, J. H., Forbes, M. G., Fincher, G. B., Langridge, P., and Bacic, A. (2006). An investigation of boron toxicity in barley using metabolomics. Plant Physiol. 142, 1087-1101. doi: 10.1104/pp.106.0 84053

Ruiz, J. M., Rivero, R. M., and Romero, L. (2003). Preliminary studies on the involvement of biosynthesis of cysteine and glutathione concentration in the resistance to B toxicity in sunflower plants. Plant Sci. 165, 811-817. doi: $10.1016 /$ S0168-9452(03)00276-0

Sakamoto, T., Inui, Y. T., Uraguchi, S., Yoshizumi, T., Matsunaga, S., Mastui, M., et al. (2011). Condensin II alleviates DNA damage and is essential for tolerance of boron overload stress in Arabidopsis. Plant Cell 23, 3533-3546. doi: $10.1105 /$ tpc.111.086314

Shi, D. Q., and Yang, W. C. (2010). "Pollen germination and tube growth," in Plant Developmental Biology - Biotechnological, Perspectives, eds E. C. Pua and M. R. Davey (Berlin: Springer), 245-282.

Showalter, A. M. (2001). Arabinogalactan-proteins: structure, expression and function. Cell. Mol. Life Sci. 58, 1399-1417. doi: 10.1007/PL00000784

Sotiropoulos, T. E., Molassiotis, A., Almaliotis, D., Mouhtaridou, G., Dimassi, K., Therios, I., et al. (2006). Growth, nutritional status, chlorophyll content, and antioxidant responses of the apple rootstock MM 111 shoots cultured under high boron concentrations in vitro. J. Plant Nutr. 29, 575-583. doi: $10.1080 / 01904160500526956$

Sutton, T., Baumann, U., Hayes, J., Collins, N. C., Shi, B. J., Schnurbusch, T., et al. (2007). Boron-toxicity tolerance in barley arising from efflux transporter amplification. Science 30, 1446-1449. doi: 10.1126/science.1146853

Taylor, L. P., and Hepler, P. K. (1997). Pollen germination and tube growth. Annu. Rev. Plant Physiol. Plant Mol. Biol. 48, 461-491. doi: 10.1146/annurev.arplant.48.1.461 
Tenhaken, R. (2014). Cell wall remodeling under abiotic stress. Front. Plant Sci. 5:771. doi: 10.3389/fpls.2014.00771

Voxeur, A. A., and Fry, S. C. (2014). Glycosylinositol phosphorylceramides from Rosa cell cultures are boron-bridged in the plasma membrane and form complexes with rhamnogalacturonan II. Plant J. 79, 139-149. doi: $10.1111 /$ tpj.12547

Wang, M. J., Wang, Y., Sun, J., Ding, M. Q., Deng, S. R., Hou, P. C., et al. (2013). Overexpression of PeHAl enhances hydrogen peroxide signaling in salt-stressed Arabidopsis. Plant Physiol. Biochem. 71, 37-48. doi: 10.1016/j.plaphy.2013.06.020

Wolf, S., and Greiner, S. (2012). Growth control by cell wall pectins. Protoplasma 249, 169-175. doi: 10.1007/s00709-011-0371-5

Yu, Q., Baluska, F., Jasper, F., Menzel, D., and Goldbach, H. E. (2003). Short term boron deprivation enhances levels of cytoskeletal proteins in maize, but not zucchini, root apices. Physiol. Plant 117, 270-278. doi: 10.1034/j.13993054.2003.00029.x

Yu, Q., Hlavacka, A., Matoh, T., Volkmann, D., Menzel, D., Goldbach, H. E., et al. (2002). Short-term boron deprivation inhibits endocytosis of cell wall pectins in meristematic cells of maize and wheat root apices. Plant Physiol. 130, 415-421. doi: 10.1104/pp.006163

Yu, Q., Wingender, R., Schulz, M., Baluska, F., and Goldbach, H. (2001). Short-term boron deprivation induces increased levels of cytoskeletal proteins in Arabidopsis roots. Plant Biol. 3, 335-340. doi: 10.1007/0-306-47 624-X_77

Zhang, W. H., and Renzel, Z. (1998). Determination of intracellular $\mathrm{Ca}^{2+}$ in cells of intact wheat root: loading of acetoxymethyl ester of Fluo-3 under low temperature. Plant J. 15, 147-151. doi: 10.1046/j.1365-313X.1998.0 0188.X

Zhang, Y., He, J., Lee, D., and McCormick, S. (2010). Interdependence of endomembrane trafficking and actin dynamics during polarized growth of Arabidopsis pollen tubes. Plant Physiol. 152, 2200-2210. doi: 10.1104/pp.109.142349

Conflict of Interest Statement: The authors declare that the research was conducted in the absence of any commercial or financial relationships that could be construed as a potential conflict of interest.

Copyright (c) 2016 Fang, Zhang, Xing, Zhang, Yang, Cao and Qin. This is an openaccess article distributed under the terms of the Creative Commons Attribution License (CC BY). The use, distribution or reproduction in other forums is permitted, provided the original author(s) or licensor are credited and that the original publication in this journal is cited, in accordance with accepted academic practice. No use, distribution or reproduction is permitted which does not comply with these terms. 